\title{
Large elapids and arboreality: the ecology of Jameson's green mamba (Dendroaspis jamesoni) in an Afrotropical forested region
}

\author{
Luca Luiselli ${ }^{1,2}$, Francesco M. Angelici ${ }^{1,2}$ \& Godfrey C. Akani ${ }^{3}$ \\ ${ }^{I}$ DEMETRA - Institute of Environmental Studies, Via dei Cochi 48/B, I-00133 Rome, Italy, and Italian Foun- \\ dation of Vertebrate Zoology, Via Cleonia 30, I-00152 Rome, Italy, e-mail: lucalui@iol.it; ${ }^{2}$ Ecology Re- \\ search Group (NFC-FIZV), No. 4 Adak Uko Street, Calabar, Cross River State, Nigeria; ${ }^{3}$ Department of \\ Biological Sciences, Rivers State University of Science and Technology, P.M.B. 5080, Port Harcourt, Rivers \\ State, Nigeria
}

Keywords: Dendroaspis jamesoni, Elapidae, snakes, ecology, Nigeria

\begin{abstract}
Several aspects of the ecology of Jameson's green mamba Dendroaspis jamesoni jamesoni (Traill, 1843), a large-sized arboreal elapid snake, are studied in southern Nigeria. This species is common and widespread in the region studied. On the basis of the analysis of both the habitats of capture of the various specimens and the results of a logistical regression model, it seems that this species inhabits a wide variety of habitats (including secondary forest patches and the plantation-forest mosaic), and that its local distribution is not influenced by the presence of any macrohabitat parameter. Green mambas were observed both in the dry and in the wet season, without any statistical bias toward a particular season. Adult sex-ratio was approximately $1: 1$. Males were significantly longer than females. All adult mamba dietary records involved warm-blooded prey (mainly birds), whereas young mambas fed also upon lizards and toads. Nearly all the prey eaten by adult mambas were arboreal, and thus there was no support for the recent hypothesis that adult mambas develop an orientation to forage on terrestrial rodents. Male-male combats and matings were observed in December, January, and February (dry season), and gravid females were collected in April, May, and June (wet season). Females produced 7-16 eggs (mean 10.9), and litter size was positively correlated with maternal length.
\end{abstract}

\section{Contents}

Abstract

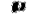

Introduction

Materials and methods

Study area ,

Data collection

Analyses

Results

Habitat and ecological distribution

Seasonal distribution of records

Population size and density

Sex ratio and sexual size dimorphism
Food habits

150

Reproductive biology

150

Discussion

Acknowledgements

References

151

153

154

\section{Introduction}

One typical corollary of the contextual presence of highly toxic venom and impressive size in snakes is great public interest in these species. Thus, it is not surprising that, compared with most of the African snake species, the large-sized highly venomous mambas (genus Dendroaspis: Elapidae) are relatively well-known (e.g. see Schmidt, 1923; Wakeman, 1955; Isemonger, 1962; Ionides and Pitman, 1965; Lloyd, 1974; Pitman, 1974; Villiers, 1975; Branch, 1988; Phelps, 1989; Angilletta, 1994; Branch et al., 1995, and references therein; Spawls and Branch, 1997).

The continuous forest zone in southern Nigeria is inhabited by Jameson's green mamba, Dendroaspis jamesoni jamesoni (cf. Villiers, 1975; Butler and Reid, 1986, 1990; Spawls and Branch, 1997; Luiselli et al., 1998c), and possibly by the western green mamba, D. viridis (Villiers, 1975; Spawls and Branch, 1997). The latter species, however, was never found by us during our long-term field research in this African country (Akani et al., 1999). The present paper provides detailed ecological data on the Jameson's green mamba in southern Nigeria, and compares the collected data with those available for other large elapid snakes from Africa and elsewhere. 


\section{Materials and methods}

\section{Study area}

The field study was carried out mainly from September 1996 to February 1999, with some data recorded even earlier, in some localities of southern Nigeria. These localities were situated in the territories of the Niger Delta (Delta, Edo, Bayelsa, and Rivers States), in Anambra State, Abia State, Akwa-lbom State, Imo State, and Cross River State (Fig. 1). These territories are in general heavily populated, with patches of rainforest interspersed among wide plantations (yam, cassava, cocoa, pineapple, banana, plantain, oil palm, etc.). The forest patches may have dry soil, or may be permanently or seasonally inundated swamp-forests. Enormous extensions of mangrove formations (Avicennia marina, Rhizophora racemosa) are found in the brackish water tracts, mainly along the rivers Benin, Forcados, Ramos, Sangana, Nun, Brass, Saint Nicholas, Santa Barbara, San Bartholomew, Sambreiro, New Calabar, Bonny, Imo, Kwa-Ibo, and Cross. Much details of both study areas environmental characteristics and climate conditions are described elsewhere (Luiselli et al., 1998a, 1998b, 1998c).

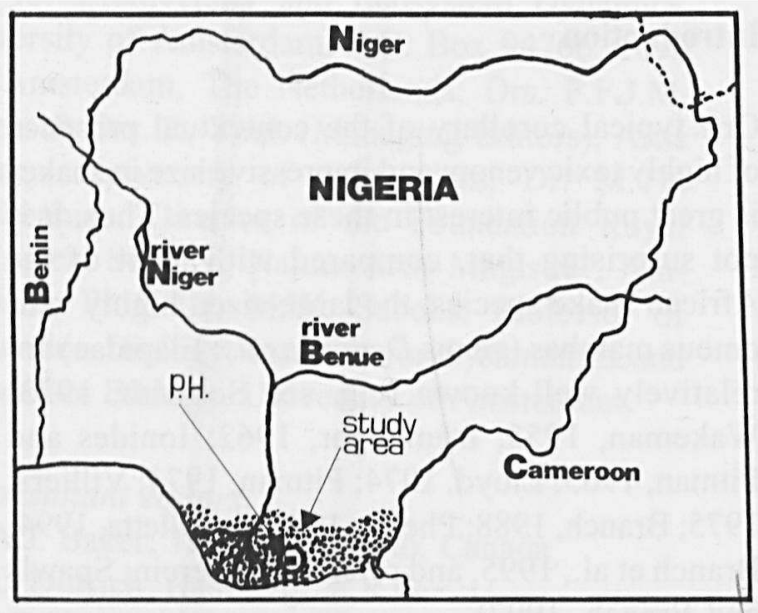

Fig. 1. Map of Nigeria showing the study area. P.H. = Port Harcourt city.

\section{Data collection}

Field trips were conducted in all types of weather. Each day, the field research lasted approximately from 8 a.m. to 6 p.m. (Lagos time). Night searches were done only rarely, because of security constraints related to the prevailing unstable political situation. Random routes to locate snakes were followed throughout every macrohabitat type available in each study area. The captured snakes were sexed and measured for snout-vent length (SVL, to the nearest $1 \mathrm{~cm}$ ) and tail length (tL). Since a negligible proportion of specimens had the tail broken $(<0.5 \%)$, for all analyses we considered the total length, i.e. $S V L+t L$.
Meteorological conditions, time (Lagos time), and habitat of each observation were recorded. Specimens found already dead (roadkilled or macheted by farmers), including those which were too damaged for any reliable body size measurement, were inspected by dissection for data on diet and reproductive condition. The same was true for some preserved specimens found in museum collections (Rivers State University of Port Harcourt, and Cross River National Park of Akampka) and in the laboratories of several high schools and hospitals (cf. "Acknowledgements"), where these specimens were transitorily stored to be used for demonstration to students. Free-ranging snakes were captured with the help of grabsticks, given the arboreal habits and the extremely dangerous nature of this species which is well-known to be highly venomous (Spawls and Branch, 1997), but, contrary to earlier reports, not very aggressive (Luiselli, Akani and Angelici, unpubl. obs.). All snake specimens captured alive were palpated in the abdomen until regurgitation of the ingested food or defecation had occurred. The prey items were identified to the lowest taxon possible. When the prey was in good condition, it was weighed by an electronic balance (to 0.1 g precision). In these cases, also the snake mass was measured. Voucher specimens are deposited in the herpetological collections of the authors (L.L. and F.M.A., collections in Rome and in Ikot-Ekpene, Nigeria; G.C.A., collection in Port Harcourt, Nigeria), in the collections of the "Monti Prenestini Natural History Museum" (Capranica Prenestina, Rome), and in the collection of the Department of Biological Sciences, Rivers State University of Science and Technology, Port Harcourt.

\section{Analyses}

Population size and density of green mambas were estimated by capture-mark-recapture procedures in a moist rainforest area of southeastern Nigeria (Eket, Akwa-Ibom State). The surface of the area used for the capture-mark-recapture procedure was 100 ha. The capture-mark-recapture study lasted 109 days, from early June to late September 1997. Snakes were individually marked by ventral scale-clipping, and painted with a white number on the back for further observations at distance without necessity of recaptures. We considered as "recaptures" (second sample) all of the later sightings of marked (i.e. dorsally painted) individuals, when at least 10 days from the date of the first capture had passed.

Population density was calculated by applying the LincolnPetersen index, with its relative $90 \%$ confidence limits (Caughley, 1977; Seber, 1982). For population size estimates, only adult specimens were considered. The Lincoln-Petersen index was used under the assumption that our mamba population was nearly without emi/immigrants. In fact, the study area is surrounded in part by a large river (Kwa-Ibo River) and in part by much deforested areas, that are hardly crossed by green mambas.

The effects of the macro-environmental parameters on the presence/absence of $D$. jamesoni in the study region were assessed by using a logistic regression model (forward stepwise conditional procedure) for discrete values (Hosmer and Lemeshow, 1989). For this analysis, we used data of presence/absence of the green 
mamba in $\mathbf{5 2}$ study sites which were accurately surveyed during our environmental works (Anonymous, 1998). The surface of each site was approximately $50 \mathrm{ha}$, and was separated from the closest surveyed site by at least $10 \mathrm{~km}$ of linear distance. Eight macro-environmental parameters were identified during these large-scale environmental studies (see Anonymous, 1998), and we checked for the eventual presence of any of them in each of the 52 sites surveyed. The designed macro-environmental parameters were as follows:

(1) primary dry forest (PDF); (2) secondary dry forest (SDF); (3) shrubland (SHL); (4) primary swamp-forest (PSF); (5) secondary swamp-forest (SSF); (6) mangrove (MGR); (7) farmland and plantation (FPL); (8) large water body (main river tract or wide lake, PWB).

The place-names, the geographic coordinates, and the macroenvironmental parameters of each of the 52 study sites are omitted in this paper to save space, but are fully presented in Luiselli and Politano (1998).

In the logistic regression model, the study areas were the cases (total $n=52$ ), the presence/absence of $D$. jamesoni was the dependent variable, and the environmental parameters were the covariates (total $n=8$ ).

All data were statistically processed by means of a SPSS (version 4.5, for Windows) personal computer package, with all tests being two-tailed and with alpha set at $5 \%$.

\section{Results}

\section{Habitat and ecological distribution}

Dendroaspis jamesoni is no doubt a common and widespread snake in southeastern Nigeria: it was found in 26 of 52 sites surveyed in the eastern axis of the Niger Delta (including sites along the courses of the rivers Imo, Bonny, New Calabar, Sambreiro, and Orashi), in several sites in the Delta, Edo, Abia and Imo States (surroundings of Aba, Okpala-Ngwa, and Owerri), in Eket, Uyo, Ikot-Ekpene, and in several sites along the Kwa-Ibo River (Akwa-Ibom State, cf. Luiselli et al., 1998c), and in Calabar, Itu, Akampka, Oban, Ekang, Ikom, and Basua (Cross River State, cf. Butler and Reid, 1986, 1990; Schmitt, 1996; Luiselli et al., ưnpubl. data).

We obtained 83 records of $D$. jamesoni for which the precise habitat at the point of capture has been recorded. Snakes were found in secondary dry forest ( $n=22,26.5 \%$ of the total sample observed), primary dry forest $(n=10,12 \%)$, primary swamp forest $(n=19,22.9 \%)$, mangrove formations $(n=$ $2,2.4 \%)$, bushy spots in the forest-plantation mosaic $(n=3,3.6 \%)$, farms and plantations $(n=23,27.7 \%)$, and suburban areas $(n=4,4.8 \%)$. As for the preserved specimens observed in high school and hospital collections $(n=11)$, it was impossible to establish the habitat of capture. However, based on interviews with school personnel, it is likely that these specimens came from highly disturbed areas around towns (suburbia and plantations). An adult roadkilled male was found in a business part of Port Harcourt city ("Mile two Diobu"), where only a few bushes and trees surrounding a wide grassy field were available to snakes.

The logistic regression model ( -2 log likelihood $=72.087$; for variables not in equation: residual $\chi^{2}=3.5, d f=8, P=0.89$ ) showed that the presence of $D$. jamesoni was not correlated significantly with any macro-environmental parameters $(P>0.15$ in all cases).

\section{Seasonal distribution of records}

We had 83 records of mambas for which the date of sighting has been recorded. There was no bias towards a particular season: $50.6 \%$ of the total number of specimens $(n=83)$ were observed in the dry season and $49.4 \%$ in the wet season (interseasonal difference at $\chi^{2}$ test with $d f=1, P>$ $0.9)$.

\section{Population size and density}

During a 109-day-long research period in Eket, we captured and marked seven adult $D$. jamesoni (six males and one female), and later recaptured five of these specimens (four males and the female) for a total of eight recaptures. All the recaptured specimens exhibited sedentary habits. The female was contacted 23 days after the first capture in a tree adjacent to the one of capture $(17 \mathrm{~m}$ of linear distance), whereas the four recaptured males were contacted again at a mean linear distance of 26.4 $\mathrm{m}$ from the sites of first capture, and in two cases inside the same tree where they were first captured.

According to a Lincoln-Petersen index calculation, population size was 11 adults $(\mathrm{SE}=2)$, and density was approximately 0.11 adults per ha-1. It should be noted that, given (i) the apparently sed- 
entary behaviour of these snakes and (ii) the relative isolation of the study forest (see "Methods"), the Lincoln-Petersen index seems to fit well with the population under study.

\section{Sex ratio and sexual size dimorphism}

Adult sex-ratio (males : females $=1.17: 1$, total $n$ =63) did not differ significantly from equality (binomial test with $d f=1: P>0.1$ ).

Excluding young specimens $(<100 \mathrm{~cm}$ total length), we measured the total length of 22 males and 27 females. There was considerable sexual size dimorphism: the males $(\bar{x}=166.4 \mathrm{~cm}, \mathrm{SD}=25.9)$ attained much larger sizes than the females $(x=$ $146.9 \mathrm{~cm}, \mathrm{SD}=20.3$ ) (Student t-test: $t=2.95$, $d f=47, P=0.0049$ ). The maximum length attained by males was $211.5 \mathrm{~cm}$, and the maximum length attained by females was $174.7 \mathrm{~cm}$.

\section{Food habits}

For dietary data 77 specimens ( 34 males, 29 females, 14 juveniles) were examined pooling together specimens captured alive in the field and specimens examined already dead. Identifiable food was found in $38.2 \%$ of the males, $13.8 \%$ of the females, and $28.6 \%$ of the juveniles, without any significant difference between wet and dry seasons ( $\chi^{2}$ test, in all cases $P>0.1$ ). Twenty-two specimens of $D$. jamesoni contained food in the guts; however, some individuals contained mote than one prey item. From specimens shorter than $100 \mathrm{~cm}$ total length we removed 7 prey items, and from specimens longer than $100 \mathrm{~cm}$ we removed 27 prey items (Table I). Most snakes did not contain more than one prey category (i.e. birds and mammals, or birds and reptiles, etc), but a large male $208 \mathrm{~cm}$ long had one squirrel (Heliosciurus sp.) and one indetermined Passeriformes in the stomach. There was a positive correlation between log snake size (mass, in $\mathrm{g}$ ) and log prey size (mass, in g) (Spearman's $r=0.32, n=20, P<0.01$ ), and the variance in prey size increased significantly with snake size (ANOVA: $P<0.05$ ).
Table I. Summary of the dietary data collected from Jameson's green mambas, shorter and longer than $100 \mathrm{~cm} \mathrm{TL}$, in southeastern Nigeria. For more details, see text.

\begin{tabular}{lcc}
\hline Prey category & $<100 \mathrm{~cm}$ & $>100 \mathrm{~cm}$ \\
& $N$ & $N$ \\
\hline AMPHIBIA & & \\
$\quad$ Bufo sp. & 1 & 0 \\
REPTILIA & & \\
$\quad$ Agama agama & 4 & 0 \\
AVES & & \\
$\quad$ Dendropicos sp. (juv.) & 0 & \\
$\quad$ Cisticola sp. (ad.) & 0 & 3 \\
Cisticola sp. (juv. & 0 & 3 \\
Passeriformes indet. & 0 & 6 \\
Streptopelia semitorquata & 0 & 1 \\
Hatchlings (undet. species) & 0 & 5 \\
MAMALIA & & \\
Crocidura poensis & & \\
Lemniscomys striatus & 1 & 0 \\
Rodentia (indet.) & 0 & 1 \\
Heliosciurus sp. & 1 & \\
Scotonycteris zenkeri & 0 & 2 \\
TOTAL & 0 & 2 \\
\hline & & 7 \\
\hline
\end{tabular}

\section{Reproductive biology}

Combats between males and matings were observed during the dry season (December, January, and February), both on the ground and on the trees. Combats involved two individuals in four cases, and three individuals in a single case, and always occurred during the central daylight hours (11.15 to 15.50). Dissection of female snakes found dead in the field, in bush-meat markets of local people (cf. Akani et al., 1998), and in school collections provided data on the seasonal reproductive timing and on the clutch sizes. Gravid females were collected in April $(n=4)$, May $(n=6)$, and June $(n=$ 5). One additional gravid female was captured in an unknown date. Adult females captured in other periods of the year (1 in February, 1 in March, 3 in May, 1 in July, 1 in September, 4 in November, and 1 in December) were not pregnant. The smallest female carrying eggs was $119 \mathrm{~cm}$ total length, and there was a highly significant positive correlation between maternal length and litter size (Table 
Table II. Summary of the reproductive data collected from female Jameson's green mambas in southeastern Nigeria. The statistics of the regression between maternal length and litter size are also presented.

\begin{tabular}{|c|c|c|c|}
\hline Parameter & $X(\mathrm{~cm})$ & $S D$ & $n$ \\
\hline $\begin{array}{l}\text { Female total length } \\
\text { Range (cm) } 119 / 179\end{array}$ & $145.8 \mathrm{~cm}$ & 22.6 & 16 \\
\hline $\begin{array}{l}\text { Litter size } \\
\text { Range } 7 / 16\end{array}$ & 10.9 & 3.11 & 16 \\
\hline \multicolumn{4}{|c|}{$\begin{array}{l}\text { Regression statistics: } \\
\text { Equation: litter size }=-7.89+0.128 \times \text { total length } \\
r=0.935 ; \text { adjusted } r^{2}=0.865 ; n=16 \\
\text { ANOVA: } F=91.13 ; d f=1,13 ; P=0.0015\end{array}$} \\
\hline
\end{tabular}

II). Reproductive data concerning the examined females are summarized in Table II. We did not collect data on the period of egg-laying in freeranging green mambas. However, oviposition of four gravid specimens housed in an outdoor enclosure in Calabar (Cross River State) during 1998 occurred respectively on $6,16,28$ June, and on 22 July. Oviposition of free-ranging specimens should most probably occur also between June and July. Mamba eggs were found in the field just three times (24 June 1997, 14 July 1997, and 2 July 1998). In all cases they were excavated by chance from holes in abandoned termite nests at forest clearings.

\section{Discussion}

Dased on (i) the wide variety of the habitats of sightings, (ii) the wide distribution of the species in the study region, and (iii) the results of the logistical regression model (no macro-environmental parameter influencing this species' presence), we stress that $D$. jamesoni is no doubt a habitat generalist, which is very well adapted to persist even in very disturbed forest patches, including sites around towns, villages and human habitations. The fact that a single specimen was found in a strongly urbanized area of Port Harcourt city suggests that small sub-populations of Jameson's mambas can survive in very small portions of suitable area (less than 2 ha surface). In this regard, the Jameson's mamba fits well into the "general picture" of the green mambas ( $D$. viridis, $D$, angusticeps), which are said to persist even in areas after forest has been felled, providing there are still thickets and trees to hide in (Spawls and Branch, 1997). The same is not true for the black mamba, D. polylepis, which occurs mainly in open savannas, but rarely around disturbed areas (cf. Spawls and Branch, 1997). The persistence of green mambas in strongly urbanized areas could locally place a serious problem to the human population, given that the fate of mamba envenomation is often lethal (Spawls and Branch, 1997).

The lack of interseasonal differences in the distribution of mamba sightings demonstrates that these snakes are active the year-round, without showing any diapause period during the dry months. This pattern is not general among large-sized arboreal snakes of the Nigerian rainforest: in fact, it is not consistent with that exhibited by Boiga blandingi (cf. Luiselli et ał., 1998b), Boiga pulverulenta, Dispholidus typus, and Thrasops flavigularis (cf. Angelici et al., unpublished data), but it is with that exhibited by Rhamnophis aethiopissa (cf. Angelici et al., in prep.) and Pseudohaje goldii (cf. Angelici et al., unpublished data). It is likely that the interaction of the traits "large body size" and "arboreality" is not significantly correlated with any specific annual activity pattern (all-year-roundactivity or dry-season-suspended-activity) in Afrotropical snake species.

Data on both population sizes and density of green mambas in Eket could be not entirely representative of the various populations of this species in southern Nigeria, given the wide range of habitâts inhabited by $D$. jamesoni, and given also the many problems associated with such kinds of estimates applied to free-ranging snake populations (cf. Parker and Plummer, 1987). Assuming that the population density of mambas in our study site and that the densities of many other snake species studied elsewhere (cf. Parker and Plummer, 1987 for a review) are at least reasonable estimates of actual densities, it should be noted that $D$. jamesoni had a population density lower than that reported for most species. The low population density of mambas in Eket is likely to be due to multiple reasons. Firstly, it could be due to the very large size of these arboreal elapids, as higher densities of small snakes 
compared with large snakes should be expected (Peters and Wassenberg, 1983; Parker and Plummer, 1987). Secondly, it could be attributable to the scarcity of spatial and trophic resources availability, as Jameson's mambas are syntopic with some other large arboreal snake species, which can be potential ecological competitors (Luiselli et al., 1998c). However, given that the Jameson's mamba (i) is a ponderous climber whose great size enables it to go very high in big forest trees (20-30 $\mathrm{m}$ or more from the ground, Luiselli et al., unpublished observation) and (ii) has a cryptic green colouration, it is also possible that only a relatively small portion of the individuals of the area have been marked, despite the strong field effort (on average 10 man-hours per field-day) and the relatively long research period (109 field days). The fact that only one female was captured is intriguing but unexplicable at the present time. Based on pilot telemetric studies (Angelici et al., unpublished data), we suspect that the relative scarcity of females versus males depends on the fact that females prefer to rest in higher strata of the forest canopy, whereas males could be easily found at the lower branches or even on the ground. Intersexual differences in vertical utilization of the available space were observed also in another snake species from the Nigerian rainforest (Luiselli and Angelici, 1998). In any case, since no detailed data on population densities is available for any other Dendroaspis species, interspecific comparisons of these issues cannot be done. According to Spawls and Branch (1997), D. angusticeps populations from coastal Kenya and southern Tanzania average 2- $\beta$ snakes per ha, but it is not clear (i) whether juveniles are excluded from these estimates, and (ii) which type of statistical estimation was used to generate this mean density value.

The lack of biased sex-ratio in adult green mambas is consistent with data available for many other snake populations studied to date, including green mambas from elsewhere (Phelps, 1989) and other large elapids as well (see.Shine et al., 1996).

As previous authorities stated that male and female Jameson's mambas attain similar body sizes (Schmidt, 1923; Isemonger, 1962; Pitman, 1974), the occurrence of a male-larger sexual size dimorphism (SSD) in our populations is surprising. The possible causes of the discrepancy between our and previous authors' data sets are various. It is possible that this discrepancy depended on (i) geographical variation within the species, or (ii) flunk statistical results. If hypothesis (i) is correct, it is likely that such geographical variation may be related to the sexual behaviour of the various populations of this species (see Shine, 1994a), so that male-larger SSD should occur in the populations exhibiting male-male combats for access to females, whereas minor SSD should occur in the populations without such combat behaviours (see also Shine, 1994a). In fact, combats between male $D$. jamesoni have already been reported in the literature (Leloup, 1964), and male combat and male superiority in body sizes are common among large Australian elapids (Shine, 1977, 1978; Shine and Covacevich, 1983). If hypothesis (ii) is correct, the differences observed between our and previous authorities' data sets should depend on the fact that we considered for our body size estimates only the adult specimens, whereas these previous authorities pooled together both adult and juvenile mambas or cited only the maximum length observed in the two sexes (cf. Schmidt, 1923; Isemonger, 1962; Pitman, 1974). The maximum size in our sample was also clearly attained by males. In this case, it is obvious that our method is the more reliable, as body sizes of immature snakes depend rather on their age than on their sex.

Although our records indicate that green mambas may prey on terrestrial organisms (e.g. shrews and toads), it is clear that most of their preys are arboreal (e.g. squirrels, fruit-bats, birds, etc.), especially when the snakes are adults. It is also clear that most of the prey eaten by green mamba species is warm-blooded (see also Schmidt, 1923; Wakeman, 1955; Lloyd, 1974; Pitman, 1974; Villiers, 1975; Phelps, 1989; Branch et al., 1995, and references therein). Moreover, our data partially confirm Chiszar et al.'s (1994) suggestion that juvenile and adult green mambas $(D$. angusticeps in the case of Chiszar et al.'s data) rely on partially different foods, with more ectothermic prey taken by the juveniles. However, based on our dietary data, we strongly agree with Branch et al. (1995) that it is unlikely that adult green mambas develop a taste for terrestrial rodents, and 
we disagree with Chiszar et al. (1994) that such a remarkable ontogenetic shift in foraging behaviour should be a widespread ecological trait in green mambas. In fact, the presence of a few terrestrial rodent prey in adult green mambas (one single case in our data: Lemniscomys striatus) need not infer terrestrial foraging as the prey items may have been ambushed from above, or have entered trees for feeding or breeding (Branch et al., 1995). The pattern of prey-size/snake-size relationships exhibited by Jameson's mambas was the "ontogenetic shift in lower size limit" (sensu Arnold, 1993), which is not uncommon among large-sized snake species (for a review, see Arnold, 1993). Concerning the foraging strategy, it is likely that Jameson's mambas exhibit a typical ambush predation (see also Angilletta, 1994, for D. angusticeps). In fact, we noticed sedentary habits both in the specimens recaptured during our capture-mark-recapture study in Eket and in the few radiotracked individuals monitored during 1998 and 1999 (Angelici et al., unpublished data).

The strong seasonality of reproductive periods exhibited by Jameson's mambas (mating in the dry season, and ovipositions in the wet season) mirrors data available for $D$. viridis, which is ecologically similar to $D$. jamesoni (Phelps, 1989), and is found in the rainforests of western Africa (Spawls and Branch, 1997). Moreover, it is likely that the majority of the adult females are able to reproduce every year, given that most of the females captured in April-June were carrying eggs. The number of eggs produced by Jameson's mambas is similar to that reported for other Dendroaspis species (6-17, cf. Spawls and Branch, 1997), and is also consistent with that of the large-sized Oxyuranus species (Shine and Covacevich, 1983), which show strong morphological, behavioural, and ecological convergence with African mambas (Branch et al., 1995). The smallest female mamba to produce eggs was a relatively small specimen (119 $\mathrm{cm}$ total length) compared to the maximum size attained by the species (up to $2.5 \mathrm{~m}$, probably even more, cf. Spawls and Branch, 1997). This may be explained by the general pattern of elapid snakes that large species mature when they are relatively small (i.e. at a low proportion of their maximum size) whereas smaller species tend to delay matu- rity until they have attained a higher proportion of their maximum body length (Shine, 1978; 1994b).

Offspring size in $D$. jamesoni is unknown, but is said to be possibly around $30 \mathrm{~cm}$ length (Spawls and Branch, 1997). Unfortunately, we did not collect any such small mamba from the wild (the smallest specimen found by us was $58.8 \mathrm{~cm}$ long, and was captured in late April). Thus, we cannot confirm whether the offspring size given by Spawls and Branch (1997) is correct, and we cannot establish the period of the year when the eggs actually hatch. This lack of information is a hard shortcoming to understand the rates of growth in these large-sized snakes. Despite direct evidence is lacking, we suspect that rapid growth is attained in free-ranging mambas. In fact: (i) green mambas are found in warm climates with activity and feeding occurring year-round (see data in this paper), (ii) of 102 specimens for which data are available (including specimens collected and measured, or just sighted) only two (1.9\% of the total) were obviously less than $70 \mathrm{~cm}$ long. This scarcity of very small individuals suggests that snakes grow rapidly through this range of small body sizes, the same being true for other large-sized elapids from elsewhere (Shine and Covacevich, 1983). However, considering that Jameson's mambas are arboreal and cryptically coloured, it is well possible that the presence of very young specimens in our sample of collected or just sighted records is strongly biased (underestimated) because of the difficulty to detect such animals in the forest canopy.

\section{Ackriowledgements}

We are indebted to several companies which supported our continued research in Nigeria. In particular, we extend our thanks to "Agip-Petroli S.p.A." (Milano), "Aquater S.p.A." (S. Lorenzo in Campo), "T.S.K.J. Nigeria Ltd." (Port Harcourt), "NAOC Ltd." (Port Harcourt), "Ecosystem s.r.1," (Bari), "Amertex Oil and Gas Ltd." (Lagos), "Italian Foundation of Vertebrate Zoology" (Rome), and "Demetra S.p.A." (Fano and Rome). We spent much pleasant time in the field with E. Politano, I.F. Barieenee, B. Ekeke, L.D. Otonye, D. Capizzi, A. Pazienti, G. Paoloni, L. Rugiero, J.S. Ekanem, B. Egbide, L. Ude, L. Bikikoro, B. Bolton, C. Effah, M.A. Inyang, S. Kalio, A. Sigismondi, and Z. Tooze: they provided us with helpful observations. The principals of the following colleges and hospitals are thanked for permitting examination of some preserved specimens: Girls" 
High School (Akpabuyoh), Connelia Connelly College (Uyo), Government High School (Ikot-Ekpene), Federal Government Girls'College (Abonnema), Girls' Hïgh School (Obot-Itu), Boys" High School (Ikot Obong Edong), Federal Government College (Port Harcourt), Owerri High School (Owerri), Union Secondary School (Itu), Ebony Hospital (Port Harcourt), Emmanuel Hospital (Eket), and University of Calabar Teaching Hospital (Calabar). Joe Butler and Berry Hughes are thanked for helpful comments and exchange of information. Dr. Annie Zuiderwijk (University of Amsterdam) and Dr. Massimo Capula (Zoological Museum, Rome) offered helpful critical comments on a previous version of the manuscript.

\section{References}

Akaní GC, Luiselli L, Angelici FM, Politano E. 1998. Bushmen and herpetofauna: Notes on amphibians and reptiles traded in bush-meat markets of local people in the Niger Delta (Port Harcourt, Rivers State, Nigeria). Anthropozoologica 27: 21-26.

Akani GC, Luíselli L, Politano E. 1999. Ecologícal and conservation considerations on the reptile fauna of the eastern Niger Delta (Nigeria). Herpetozoa 11: 141-153.

Anonymous. 1998. Technical report for assessing the environmental impact of LNG Liquified Gas Project in south-eastern Nigeria. Lagos: E.N.I. Press

Angilletta MJ. 1994. Sedentary behavior by Green Mambas Dendroaspis angusticeps. Herpetol. Nat. Hist. 2: 105-111.

Armitage WW. 1965. Observations on differences in morphology and behaviour of Dendroaspis angusticeps and D. polylepis. J. Herp. Assoc. Africa 1: 12-16.

Arnold SJ. 1993. Foraging theory and prey-size-predator-size relations in snakes. In: Seigel RA, Collins JT, eds. Snakes: Ecology and Behavior. New York: McGraw Hill, 87-114.

Branch B. 1988. Field Guide to the Snakes and Other Reptiles of Southern Africa. London: New Holland Publ.

Branch WR, Haagner GV, Shine R. 1995. Is there an ontogenetic shift in mamba diet? Taxonomic confusion and dietary records for black and green mambas (Dendroaspis: Elapidae), Herpetol. Nat. Hist. 3: 171-178.

Butler JA, Reid J. 1986. Habitat preferences of snakes in the Southern Cross River State, Nigeria. In: Rocek Z, ed. Studles in herpetology. Prague: Charles University, 483-488

Butler JA, Reid J. 1990. Records of snakes from Nigeria. Nigerian Field 55: 19-40.

Caughley G. 1977. Analysis of Vertebrate Populations. New York, John Wiley.

Chiszar D, Mehaffey D, Antonio F, Smith HM. 1994. Strikeinduced chemosensory searching in eastern green mambas (Dendroaspis angusticeps), Bull. Maryland Herpetol. Soc. 30: 149-155.

Hosmer DW, Lemeshow S. 1989. Applied logistic regression. New York: John Wiley

Ionides CJP, Pitman CRS. 1965. Notes on three East African venomous snake populations. Puku 3: 87-95.
Isemonger RM. 1962. Snakes of Africa. Cape Town: Books of Africa.

Leloup P. 1964. Observations sur la reproduction du Dendroaspis jamesoni kaimosae (Loveridge). Bull. Soc. Roy. Zool. Anvers 33: 13-27.

Lloyd CNV. 1974. Feeding behaviour in the green mamba Dendroaspis angusticeps. J. Herpetol. Assoc. Africa 12: 12 16.

Luiselli L, Akani GC, Angelici FM, Barieenee IF. 1998a. Reproductive strategies of sympatric Bitis gabonica and Bitis nasicornis (Viperidae) in the Niger Delta (Port Harcourt, Nigeria): preliminary data. Amphibia-Reptilia 19: 223-229.

Luiselli L, Akani GC, Barieenee IF. 1998b. Observations on habitat, reproduction, and feeding of Boiga blandingi (Colubridae) in south-eastern Nigeria. Amphibia-Reptilia 19: 430436.

Luiselli L, Akani GC, Capizzi D. 1998c. Food resource partitioning of a community of snakes in a swamp-rainforest of south-eastern Nigeria. $J$. Zool. London 246: 125-133.

Luiselli L, Angelici FM. 1998. Sexual size dimorphism and natural hìstory traits are correlated with intersexual dietary divergence in royal pythons (Python regius) from the rainforests of southeastern Nigeria. Ital. J. Zool, 65: 183185.

Luiselli L, Politano E. 1998. Update of distribution, status, and habitats of crocodiles and chelonians in the eastem Niger Delta (Port Harcourt region of Nigeria), with a planning for conservation and management. Agip $\mathrm{Co}$. Milano: Environmental Reports.

Meirte D. 1992. Cles de determination des serpents d'Afrique. Ann. Sci. Zool. Mus. Royal Afr. Centr., Tervuren 267: 1-152.

Parker, W.S. and Plummer, M.V. 1987. Population ecology. In: Seigel RA, Collins JT, Novak SS, eds. Snakes: Ecology and Evolutionary Biology. New York: MacMillan, 253-301.

Peters RH, Wassenberg K. 1983. The effect of body size on animal abundance. Oecologia 60: 89-96.

Phelps T. 1989. Poisonous snakes. Revised edition. London: Brandford.

Pitman CRS. 1974. A Guide to the Snakes of Uganda. Revised Edition. Codicote: Wheldon and Wesley.

Schmidt KP. 1923. Contributions to the herpetology of Belgian Congo based on the collection of the American $\mathrm{Mu}$ seum Congo expedition. Part II. Snakes. Bull. Amer. Mus. Nat. Hist. 49: 1-146.

Schmitt K. 1996. Zoological survey in the Oban Division, Cross River National Park. Calabar: Oban Hills Programme Reports.

Seber GAF. 1982. The estimation of animal abundance and related parameters, London: Charles Griffin and Co. Ltd.

Shine R. 1977. Reproduction in Australian elapid snakes: $I$. Testicular cycles and mating seasons. Aust. J. Zool. 25: 647653.

Shine R. 1978. Growth rates and sexual maturation in six species of Australian elapid snakes. Herpetologica 34: 73-79.

Shine R. 1994. Sexual size dimorphism in snakes revisited. Copeia 1994: 326-346. 
Shine R. 1994b. Allometric patterns in the ecology of Australian snakes. Copela 1994: 851-867.

Shine R, Covacevich J. 1983. Ecology of highly venomous snakes: The Australian genus Oxyuranus (Elapidae). $J$. Herpetol. 17: 60-69.

Shine R, Harlow PS, Branch WR, Webb JK. 1996. Life on the lowest branch: Sexual dimorphism, diet, and reproductive biology of an African twig snake, Thelotomis capensis (Serpentes, Colubridae), Copeĩa 1996: 290-299.
Spawls S, Branch B. 1997. The Dangerous Snakes of Africa. London: Blandford.

Villiers A. 1975. Les Serpents de l'Ouest Africain. Initiations Afrìcaines, I.F.A.N. Dakar, 1-195.

Wakeman BN. 1955. Uganda's poisonous snakes: further observations on feeding habits. Uganda Joumal 30: 101-103.

First draft received: 30 March 1999 